\title{
SIV-1b
}

\section{Implementation approaches for distributed energy management systems in production}

\author{
Jörg Reiff-Stephan ${ }^{1}$
}

The energy management of manufacturing facilities must be taken increasing account for an efficient operation within a production process. Future efforts and solutions will focus on improvement of the process stability and on cost reduction to meet the needs of successfully compete in local and global markets especially for SME. The paper describes an approach for manufacturing facilities using an example for thermoprocessing equipment. For this purpose, the TPS-principle Jidōka is used, the mechanism of self-adapting limit setting as well as an implementation is presented prototypically.

\section{Introduction}

In order to meet the challenges of future value-added networks, manufacturing companies are increasingly dependent on the collection of energy data and its processing in efficient process chains $[1,3,5,13]$. Industrial energy management systems are therefore becoming increasingly important. The IT networking of production processes is being strongly promoted by the strategies and enablers of Industrie4.0. Process and service orientation, interoperability, horizontally and vertically networked information chains as well as data transmission systems that function in real time with high availability are some of the building blocks for an (energy) efficient production system [2]. Considering the study [14], which was conducted under the auspices of acatech, the three main areas of development are data evaluation and analysis, process management and customer relationship management. Due to this, the following approaches are shown that could enable initial implementation approaches to efficient energy management.

\section{Requirement analysis}

\subsection{Areas of responsibility}

For an extension of existing productive structures to include the functionality of an energy management system, it is necessary to obtain a clear picture of the possibilities that the existing production system already offers. The mentioned acatech-competence study makes it clear that process management and process orientation in the German economy obviously still represent inadequately solved challenges, although these have long been vacant, regardless of Industrie4.0 [14].

It will be essential to be clear about the tasks of energy management in the implementation of DIN EN ISO 50.001 and DIN EN 16247-1 (Figure 1). Primary economic parameters such as

\footnotetext{
${ }^{1}$ Prof. Hon.-Prof. Dr.-Ing. Jörg Reiff-Stephan, TH Wildau, Wildau - Germany
} 
energy prices or key figures on competitiveness are to be considered equally important to the legal and normative requirements resulting from the scarcity of resources and environmental pollution. Last but not least, the certification as an energy-saving company can improve your own image. It is important that this process of analysis and deduction is considered a continuous process of improving the production system. Primary objectives describe the reduction of energy costs as well as the maintenance of a stable, available process.

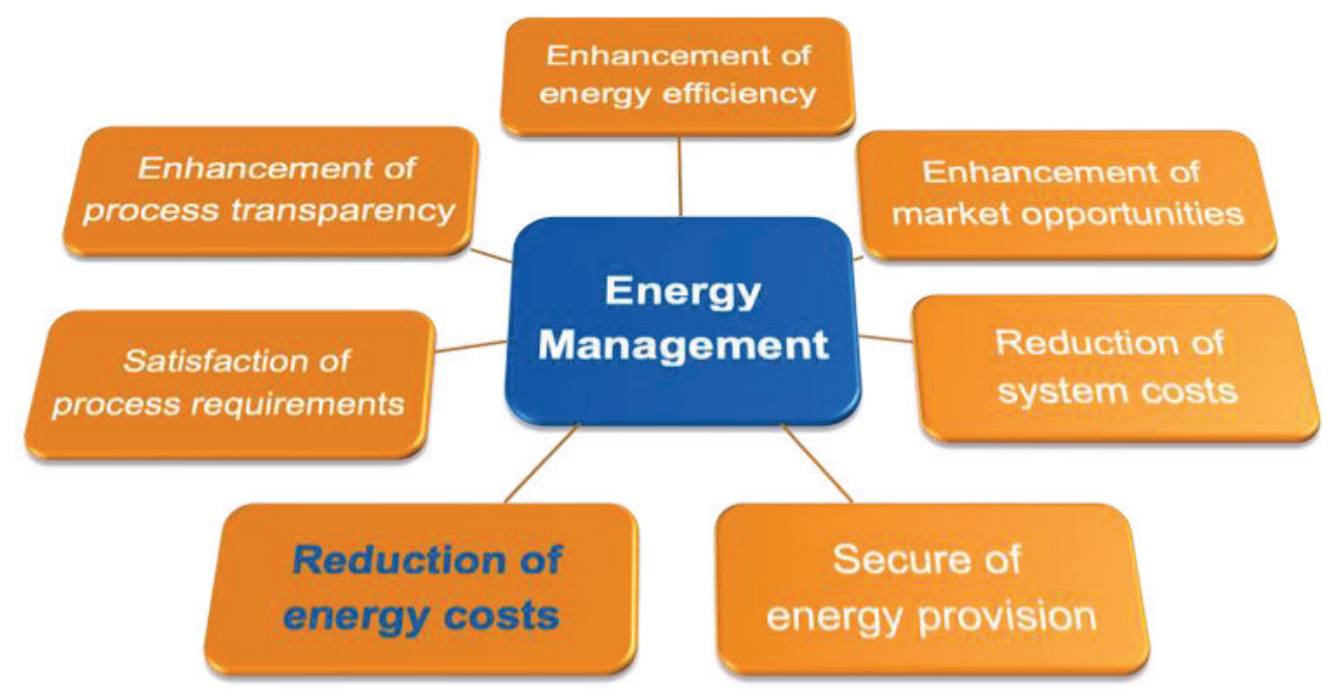

Figure 1: Aims of energy management systems

\subsection{Enabler}

The capturing, communication and computation of energy-relevant parameters becomes a decisive requirement for the efficient management of energy processes. The rapidly developing digitalization of value-added networks offers excellent starting points for this. The IT integration of things (technical entities), data and services has both vertical and horizontal characteristics [12]. Cyberphysical production systems (CpPS) are being developed, which describe the connection of the information and software components with the mechanical, electronic entities [4].

In detail, vertical integration in this context includes automated decision making across the levels of the automation pyramid, for example to make adjustments of technological information on technical entities (such as motors or oven systems) directly usable for control information at the point of use. In this respect, the horizontal integration is carried out in such a way that operational information from the services (e.g. with the help of energy monitoring systems) together with contextual information (e.g. supply information from the energy exchange) flow directly into the respective production without stopping backwards along the value chain. This integration also intelligently overcomes company boundaries, so that each communication partner can flexibly decide which data granularity is provided. Furthermore, energy suppliers, for example, could obtain forward-looking, real-time information about the requirements of their customers. 
Intensive work is being done on methods and tools for querying and providing data in real time. There are several protagonists who, through standardization efforts, try to offer a corresponding general solution. At present, the standard DDS (Data Distribution Service) of the Object Management Group [6] realizes these hard real-time requirements for distributed systems up to application level. The standard has been further developed as open source in many areas, but due to its specific orientation it cannot be applied in all places within the information network. In this respect, the OPC Foundation's OPC-UA (Open Platforms Communication - Unified Architecture) standard is a very broadly based industrial M2M communication protocol [7]. Its service-oriented architecture (SOA) enables the switching of data packets between the various participants based on the OSI layer model. The implementation of your own security services can thus be carried out very efficiently. The lack of time scalability, which currently still prevents a broad application, is being addressed within an ISO working group of the IEEE802.1. The provision of the information with a time-synchronous protocol is to be taken into account in a hard real-time system called "Time Sensitive Networks" (TSN). Which standard will be used in the CpPS application in the future will be decided based on the requirements of the actual applications.

The efficient computing of the communicated information is sometimes regulated in CpPS system by the principles of self-organisation. This is done, for example, with the help of capacity exchanges or service-oriented agent systems. Such systems control the consumption of available resources according to fixed or dynamically generated weightings and react dynamically to changing conditions. Depending on the process, however, the human entity remains the decision maker. In such cases the human being is supported by the self-organized system in the form of simulated variants of different scenarios. The final choice as well as decision is then left to the human being [2].

\section{Concept study}

Based on the consideration of the distributed control architecture, a concept for energy management is presented, which does justice to the two targeted topics of cost reduction and high process stability.

\subsection{Distributed control architecture}

Value-added processes in a production system are characterized by the conversion of energy. In the predominant sense, all usable forms of energy are attributed to the provision of electrical energy. Conversion and utilization processes are regulated with control and sensor/actuator entities at the distributed points of use in the value-added process. In the future, these entities can be dynamically adapted to changed process conditions, rearranged or supplemented within the framework of distributed architectures in a heterogeneous production environment.

A hardware PLC could thus become less important in the future, since sensors and actuators can interact with the control software in the cloud using IP-based addressing via standardized communication nodes (Figure 2). The implementation of new field devices requires only minimal effort in terms of wiring. This is then limited to the connections to the power supply and the communication node. In the case of energy-autonomous wireless sensors, the wiring is 
completely eliminated. The industrial cloud of production automation is likely to have a private or hybrid structure $[9,11]$. The control network will thus preferably be limited to the company's borders, but will allow information to be exchanged with other networks as required.

With the IP-based entities the realization of horizontal as well as vertical integration in the production network becomes possible. The system presented in Figure 2 takes an industrial oven as an example and links the essential individual processes for operating it in the digital network. The idea of a virtual PLC has already been taken up here, but is not an indispensable prerequisite for energy management [9]. Regulated access from the cloud systems outside the own company as well as within the own data structures must be guaranteed by protecting the data and services against misuse such as unauthorized access, modification or destruction. In this respect, the objectives of attack security measures are to increase confidentiality, integrity and availability.

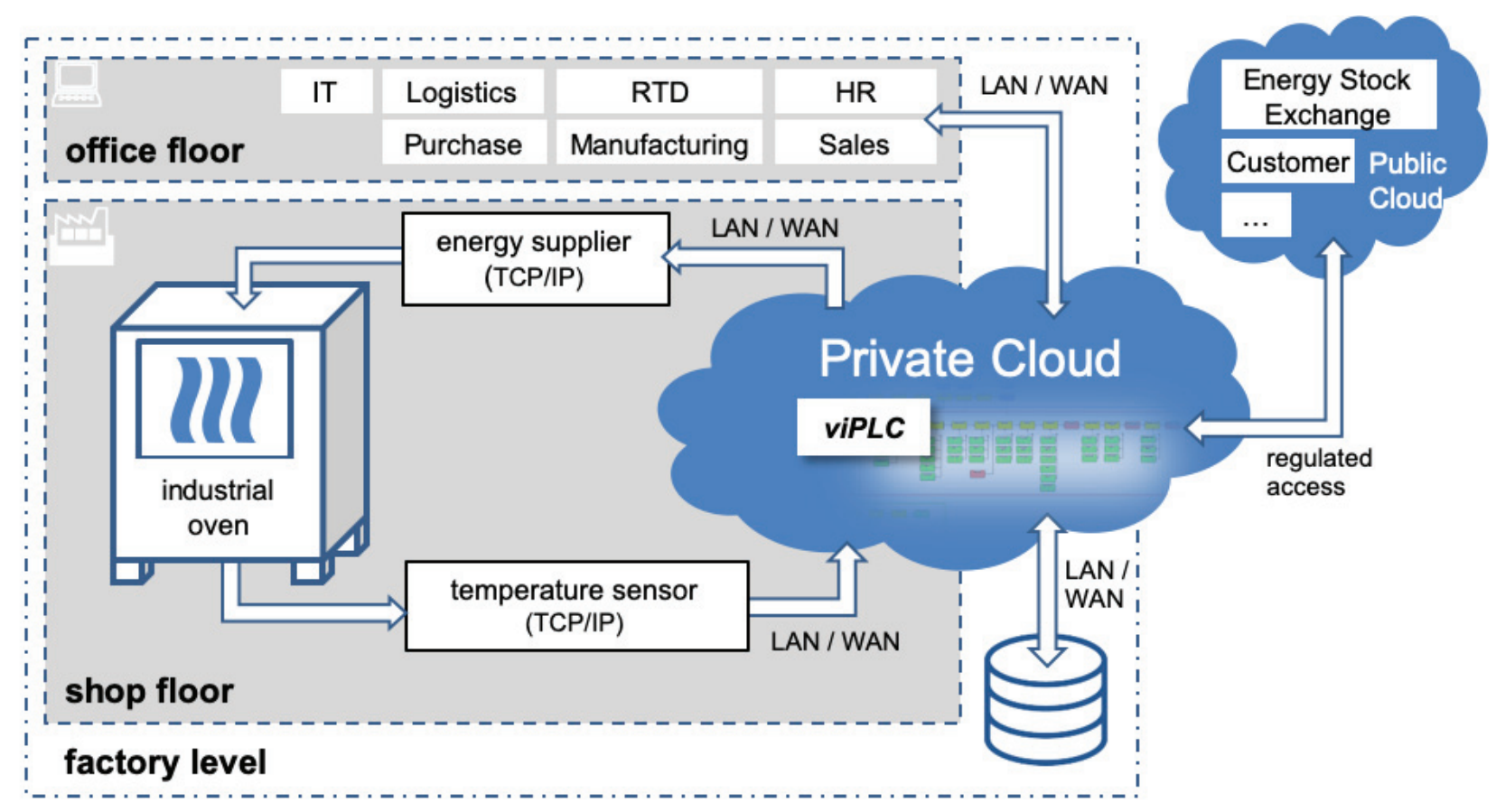

Figure 2: Information flow of a thermoprocessing plant with a cloud-based management system

\subsection{Derivation of management tasks}

The process sequences are being carried out with increasingly high material and energy efficiency under business management requirements. For example, the energy profile of a process step can be used as a decision factor in production planning processes, thus avoiding load peaks in the factory's internal energy network [13]. Peak loads are sometimes caused by the switch-on processes of machines and systems. Additionally, the average load profile of the actual production process is exceeded many times over. Since the maximum values in the load profile directly influence the energy supply costs, intelligent load management offers high potential for cost reduction [3].

With the knowledge of the cost-optimal provision of electrical energy on the energy exchange, orders can be introduced into the production process. For this purpose, the price development 
on the energy stock exchange can be monitored automatically via agents and the waiting process can be released into order processing.

The further aspect of process stability is considered by the exact knowledge of the current energy requirements of production plants, machines and individual assemblies and the possible, comparative temporal consideration, in order to support maintenance and repair processes $[8,10]$. For this purpose, the detection of abnormal plant conditions based on the trend analysis of energy data is used. A prerequisite for this is the ability of the existing technical entities to collect the relevant data. In this respect, the market offers a wide range of solutions for implementation. A comparison of the solutions shows that the most suitable system can be identified for the respective application [12].

Due to the exact knowledge of the current and future energy requirements of production plants, machines and individual components, the data can be processed, for example, by using the process control concept presented by the TOYOTA Production System (TPS) under the term Jidōka (Autonomation). In the event of a fault, the production process is automatically stopped:

- a production-related reject,

- damage to the production plant as well as

- other wastes such as energy inefficiencies,

avoided. For a stable process, this stop strategy, designed as a self-optimizing system, is supplemented by decision rules to support maintenance and service processes.

\section{Applications}

\subsection{Prototypical test setup}

The spectrum for applications for the use of energy data is broad. An application scenario defined with an industrial partner, which combines the above-mentioned aspects, is, for example, the improvement of energy efficiency in a thermal processing plant (see also Figure 2). The service life of thermoprocessing equipment is very long, with an operating life of up to 30 years. With regard to the outdated technologies, there is a high potential for reducing energy consumption through optimization measures. In addition to the optimization of the oven wall structure or the heating technology, intelligent control and regulation technology also leads to improved energy efficiency and process stability. Energy data can be used directly as information for the control and regulation processes of the thermal processing plant or as decision criteria for higher-level functions of production planning and control.

The implementation of the described optimization is illustrated by a laboratory demonstrator. A laboratory oven type VD from MIHM-VOGT\&CO was deliberately chosen as the thermoprocessing plant. This older construction type was renewed with regard to the sensor components in order to test the suitability of the optimization measures for applications with brownfield character. A first test setup is shown in Figure 3. 


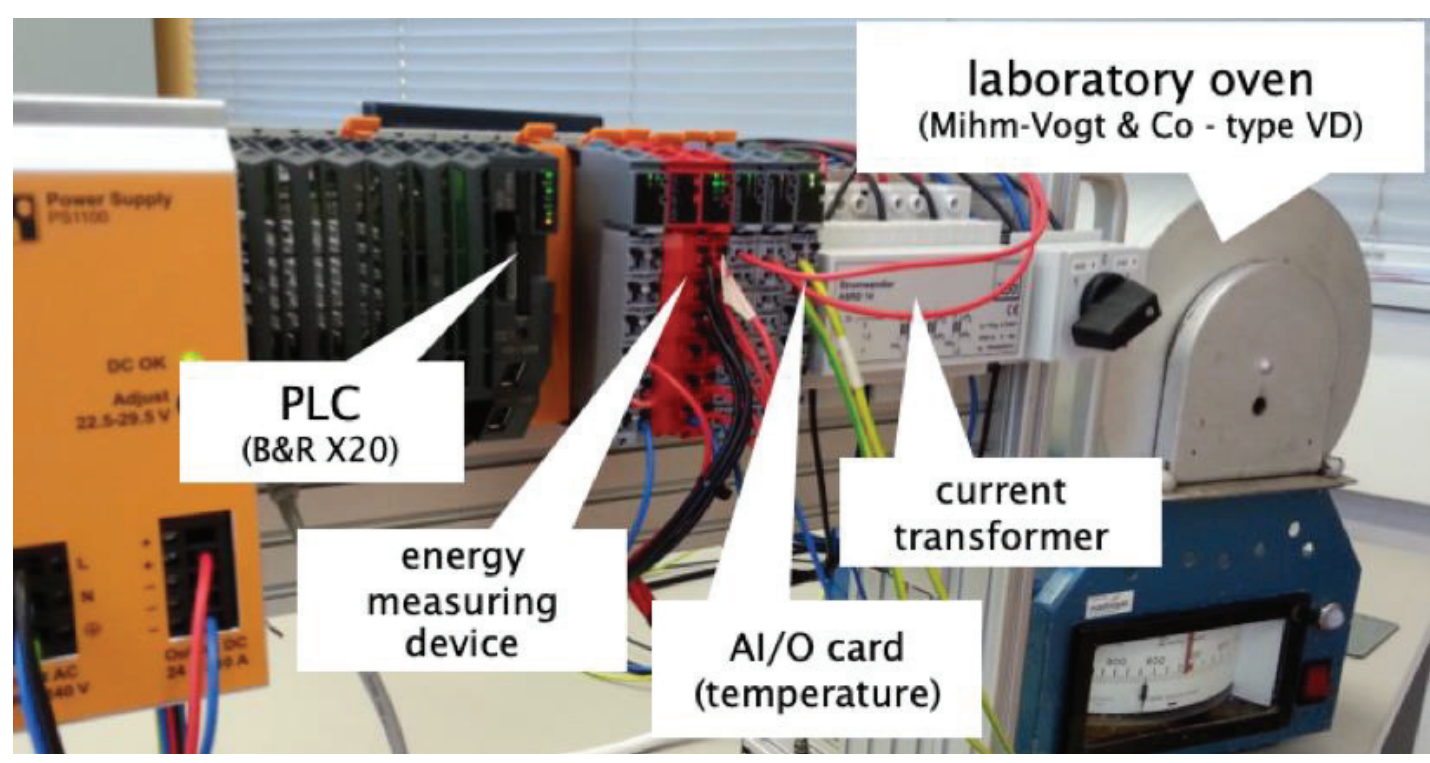

Figure 3: Prototypical test setup

The connection-programmed controller was replaced by a modularized, programmable logic controller of type X20 from B\&R AUTOMATION GMBH. The configuration has been expanded with an energy measurement card of the type X20AP3131 and an analog module for integrating the temperature sensor technology. The load currents are coupled in via a current transformer of the type ASRD $143 \times 80 / 5 A$ from MBS AG. The use of the current transformer later simplifies the conversion to the real process plant. Logically, the data is made available from the controller via an OPC-UA interface. A backup of the data is guaranteed via a relational MS ${ }^{\circledR} S Q L$ database. From this, the necessary rules for higher-level control tasks as well as the visualization including key figure formation and real-time graphs would be derived.

\subsection{Self-adapting control}

As mentioned above, the Jidōka principle can be applied to maintain process stability with optimal energy price utilization. For the application under consideration, a reference variable is, for example, the amount of energy required to carry out a thermal manufacturing process. The actual process value is continuously captured and assigned to the energetic fingerprint of the product to be manufactured, as well as being made available to higher-level control processes as a performance indicator. By means of trend analysis, the data can then be used to increase the energy efficiency of the thermal processing plant.

If, for example, for the production of individual workpieces or batches with the same process parameters, and for the thermal production process a continuously higher energy requirement is determined, this can indicate abnormal plant and process conditions. The increased energy requirement is then due, for example, to unfavorable parameterization of upstream processes, undetected thermal bridges or wear of the heating elements or wall structure inside the oven. A trend analysis is used to compare historical data with the current condition monitoring. If the values exceed the warning limit, an inspection order is automatically triggered to take account of the task of maintaining process stability. If intervention limits are exceeded, the process is automatically stopped and the causes of the diverging energy values can be searched for. 
A self-adapting control model can be specified as an example for the described technological process. By using the process parameter "active power" $(\mathrm{Pw})$, a control strategy can be described under the target criteria of energy efficiency but also as an adjustment of intervention and automatic shutdown limits. With knowledge of the actual values $\mathrm{P}_{\mathrm{w}}(\mathrm{t})$ and a trend analysis for each operating shift, a warning limit $\left(\varepsilon_{\mathrm{a}}\right)$ and a shutdown/stop limit $\left(\varepsilon_{\mathrm{h}}\right)$ will be specified as a regulating element and implemented in the process control (Fig. 4). The management system is equally capable of adjusting these limits on the basis of previous process periods. The following functional connection is made for this:

Warning limit: $\lim _{t \rightarrow t_{1}} f(t)=P_{W}(t)+\varepsilon_{a}$

Stopping limit: $\lim _{t \rightarrow t_{3}} f(t)=P_{W}(t)+\varepsilon_{h}$

Apart from energy, the main criterion will be the basic statement on the cause of the increased energy consumption. The discussion according to Figure 4 shows that by operating two shifts ( $S_{1}$ and $S_{2}$ ), the power consumption (at base load level PwGP) remains approximately stable for continuous operation. Within the third displayed period the function value $f(t)=P w(t)$ converges against the limit value $\mathrm{f}_{\left(\mathrm{t}_{1}\right)}=\mathrm{Pw}_{\mathrm{w}}+\varepsilon_{\mathrm{a}}$. Accordingly, at time $\mathrm{t}_{1}$ and when the limit value is reached, an alarm message is automatically output and a test of the system is initiated. An acknowledgement of the signal without corresponding influence $\left(Q^{+}\right)$by the operating personnel leads to a self-adaptive limit value adjustment within the controlling system of $\varepsilon_{a}{ }^{\prime}=\varepsilon_{a}+$ $\xi s \Leftrightarrow \xi s \in \mathrm{x}$ with $\mathrm{x}=$ step size. The further operation of the thermoprocessing plant in the subsequent shifts is carried out with adjusted limit values.

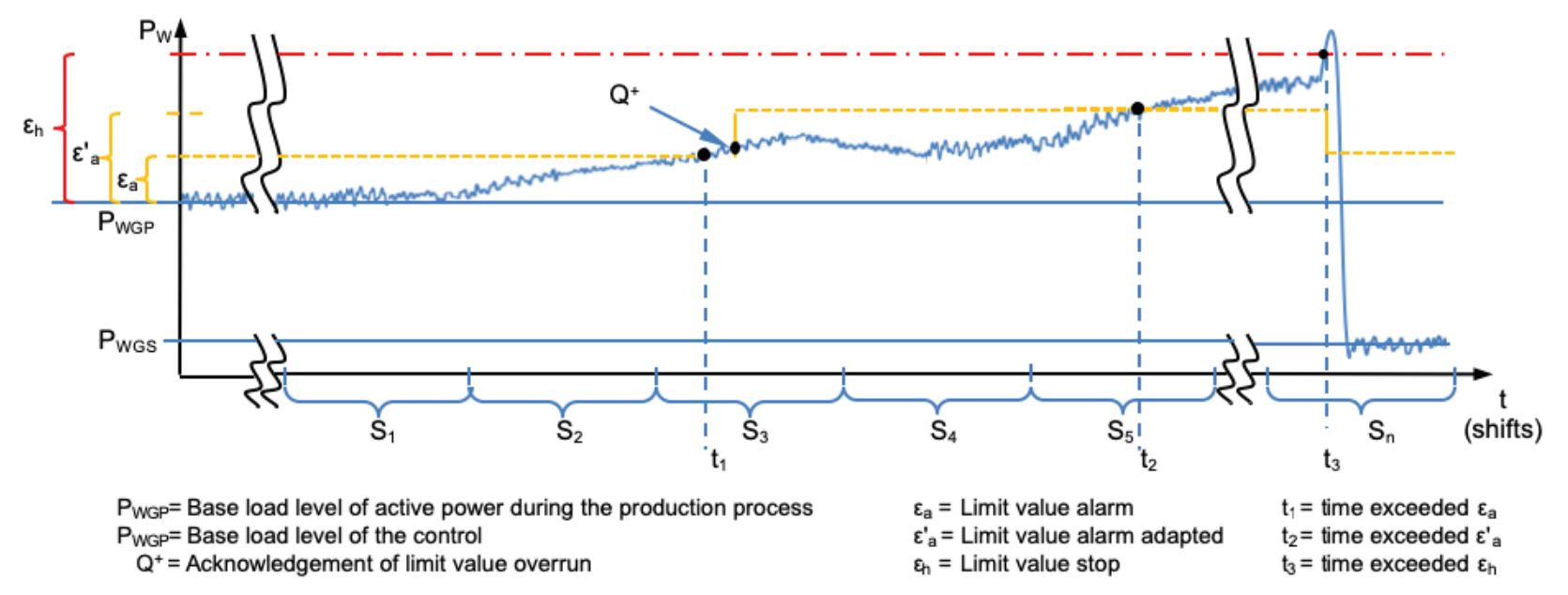

Figure 4: Functional relationship self-adapting limit value setting

The extended case of exceeding the stopping limit according to equation 2 leads to an automatic shutdown of the production system by the control and thus to a reduction of the power consumption to the basic load level of the control system (PwGs). This case occurs if, when the warning limit $\left(\varepsilon_{a^{\prime}}\right)$ is exceeded, the plant continues to operate via subsequent histories $S_{n}$ (with $\mathrm{n} \in 6 . . \mathrm{m})$ and the limit $\varepsilon_{\mathrm{h}}$ is exceeded due to a sudden rise in the relevant process variable at time t3. Due to the process, this can occur as a result of delayed reaction times by the 
maintenance personnel. After an automatic shutdown of the installation, the limit value for the warning limit $\left(\varepsilon_{a}\right)$ is automatically reset to the original value by the guidance system.

\section{Conclusion}

Energy management is increasingly considered in the design and operation of agile production systems. In particular, the Jidōka principle, in the sense of the TOYOTA production system, is being driven forward by the expanded technological possibilities of physical systems. Due to the accelerated networking of industrial structures, a broad spectrum of data is increasingly available for automated switch-off processes, for example. Thus, the detection of abnormal system states can be done by trend analyses of energy data. A prerequisite for this is the ability of the existing technical entities to collect and evaluate the corresponding data. The presented PLC-oriented overall concept enables, in addition to the measurement of energy-relevant process parameters, the provision via a flexible $\mathrm{MS}{ }^{\circledR} \mathrm{SQL}$ database and OPC-UA connection to the control platform. In the future, the design and integration of a virtual process computer in a private cloud of the plant operator is also planned. The aim will be to increase the flexibility of future production plants with high process, data and service availability.

\section{References}

[1] M. Blesl and K. Kessler: "Energieeffizienz in der Industrie." Berlin: Springer Vieweg, 2013

[2] BMBF: "Industrie 4.0. MetamoFAB (Metamorphose zur intelligenten, vernetzten Fabrik)." Retrieved on: 14.06.2020, url: http://www.metamofab.de , 2020

[3] E. Tönsing: "Energiekostenreduzierung durch betriebliches Energiemanagement". Fachartikel im Rahmen der Initiative „Energie effizient nutzen-Schwerpunkt Strom “, Wirtschaftsministerium Baden-Württemberg, 1996

[4] M. Shafie-Khah and P. Siano. "A stochastic home energy management system considering satisfaction cost and response fatigue." IEEE Transactions on Industrial Informatics 14.2 (2018): 629-638. doi: 10.1109/TII.2017.2728803

[5] W. Kahlenborn, S. Kabisch, J. Klein, I. Richter and S. Schürmann: "Energiemanagementsysteme in der Praxis: ISO 50.001: Leitfaden für Unternehmen und Organisationen." Berlin: Bundesministerium für Umwelt, Naturschutz und Reaktorsicherheit, 2012

[6] OMG: Whitebook DDS. Version 1.4 April 2015. Retrieved on: 14.06.2020, url: http://www.omg.org/spec/DDS/, 2020

[7] OPC Foundation. Whitebook OPC-UA. Version 1.04 November 2017. Retrieved on: 14.06.2020, url: https://opcfoundation.org/developer-tools/specifications-unifiedarchitecture/part-1-overview-and-concepts, 2020

[8] R. Langlois: "Modularity in technology and organization." Journal of Economic Behavior \& Organization, vol. 49. pp. 19-37, 2002

[9] R. Langmann, and M. Stiller: Industrial Cloud - Status und Ausblick. HMD Praxis der Wirtschaftsinformatik, vol. 52, pp. 647-664, Wiesbaden: Springer Fachmedien, 2015 
[10] O. Niggemann, J. Jasperneite, and A. Vodencarevic: "Konzepte und Anwendungsfälle für die intelligente Fabrik". Industrie 4.0 in Produktion, Automatisierung und Logistik. Wiesbaden: Springer Fachmedien, 2014

[11] Institut für Steuerungstechnik der Werkzeugmaschinen und Fertigungseinrichtungen: Industrielle Cloudbasierte Steuerungsplattform für eine Produktion mit cyberphysischen Systemen. Retrieved on: 07.06.2020, url: http://www.projekt-picasso.de, 2020

[12] J. Reiff-Stephan, M. Richter, and R. von Lipinski: "Intelligent sensor systems for selfoptimising production chains". Proceedings of 1st International Conference and Exhibition on Future RFID Technologies. Eger: Eszterhazy Karoly University of Applied Sciences, 2014

[13] G. Vladova, A. Ullrich and J. Reiff-Stephan: „Der Mensch im Umfeld von Industrie 4.0.“ Berlin: Springer Vieweg, 2017, S. 23-30

[14] ANSI/ISA-18.2-2009 - "Management of Energy Systems for the Process Industries"

[15] J. Reiff-Stephan, and René von Lipinski: „Energiedaten als Führungsgröße“. pp. 32-41, atp edition 58 (2016) 9 